\title{
Microstructure and wear behaviour of FeAl-based composites containing in-situ carbides
}

\author{
RAVI KANT ${ }^{1, *}$, UJJWAL PRAKASH ${ }^{1}$, VIJAYA AGARWALA ${ }^{1}$ and V V SATYA PRASAD ${ }^{2}$ \\ ${ }^{1}$ Department of Metallurgical and Materials Engineering, IIT Roorkee, Roorkee 247 667, India \\ ${ }^{2}$ Defence Metallurgical Research Laboratory, Kanchanbagh, Hyderabad 500 058, India
}

MS received 17 February 2016; accepted 25 April 2016

\begin{abstract}
Iron aluminides containing carbon are promising materials for tribological applications. Because of graphite formation at higher $(>20 \mathrm{wt} \%$ ) Al-contents the addition of carbon to FeAl-based alloys has not been successful. The graphite precipitation may be avoided by addition of $\mathrm{Zr}$ or Ti. Dry sliding wear behaviour of FeAlbased alloys containing 1-1.5 wt\% carbon with quaternary addition of Ti or $\mathrm{Zr}$ has been studied using ball-on-disk wear test. Effect of sliding speeds and applied loads is investigated and correlated with mechanical properties. Wear resistance of FeAl-based alloys is found to be significantly improved on addition of $\mathrm{Ti} / \mathrm{Zr}$. This is attributed to the high hardness of alloy carbides. The lower load-bearing capacity of graphite flakes in localized region was found to increase the wear rate of the alloy. The carbides such as $\mathrm{Fe}_{3} \mathrm{AlC}_{0.5}, \mathrm{TiC}$ and $\mathrm{ZrC}$ are embedded in the matrix after sliding wear without destruction or delamination. This significantly affects the wear resistance of FeAl-based alloys.
\end{abstract}

Keywords. FeAl-based composites; precipitation; mechanical properties; wear.

\section{Introduction}

$\mathrm{Fe}-\mathrm{Al}$ alloys are potential material for tribological applications because they have good wear resistance and high-temperature strength [1,2]. Recently, different studies showed that the carbon addition may improve the strength, creep resistance, machinability, wear resistance and resistance to environment embrittlement [3-5]. Among the Fe$\mathrm{Al}$ alloys, FeAl with ordered B2 structure shows better wear resistance as compared with $\mathrm{Fe}_{3} \mathrm{Al}$ and $\alpha$-Fe [6]. However, in B2 FeAl alloys, carbon addition leads to a loss in the strength $[7,8]$. This is attributed with the precipitation of soft graphite phase. Graphite precipitation may be prevented by addition of strong carbide formers such as $\mathrm{Ti}, \mathrm{Zr}$ and $\mathrm{Cr}[9,10]$.

It has been reported that $\mathrm{Ti}$ addition to $\mathrm{Fe}_{3} \mathrm{Al}$ and $\mathrm{FeAl}$ alloys effectively reduced the wear rate and coefficient of friction [11-13]. Further Ti addition is found to increase the yield strength and creep resistance at higher temperature [14]. Zr addition may be of interest because of very low solid solubility in $\mathrm{Fe}-\mathrm{Al}$ alloys and effectiveness in the increase in the strength due to precipitation of Laves phase $[15,16]$. In FeAl alloys containing carbon, $\mathrm{Ti} / \mathrm{Zr}$ addition may lead to formation of $\mathrm{TiC} / \mathrm{ZrC}$, thus forming a composite with the FeAl matrix.

Intermetallic alloys reinforced by carbide particles may exhibit superior wear resistance due to higher hardness of carbides $[6,12,17,18]$. However, interface bonding between particles and matrix is always an issue in composites fabricated through the powder metallurgy routes [19]. In

\footnotetext{
*Author for correspondence (kravidmt@iitr.ac.in)
}

composites prepared by melting and casting, in-situ carbides formation results in strong atomic bonding between carbides and matrix [20-22]. The present work studies the composites prepared by addition of $\mathrm{Ti}$ and $\mathrm{Zr}$ addition to $\mathrm{B} 2 \mathrm{FeAl}$ alloys containing carbon and the wear behaviour of alloys is correlated with mechanical properties.

\section{Experimental}

The FeAl-based alloys received were prepared by argon arc melting using commercially pure iron (99\%), aluminium (99.99\%), titanium $(99.8 \%)$ or zirconium to produce pancakes of $75-\mathrm{mm}$ diameter and 10-mm thickness. The nominal compositions of alloys studied are listed in table 1. For microstructural characterization, specimen sections were ground to 1500 grit and polished with alumina powder $(0.5 \mu \mathrm{m})$. The polished samples were etched with etchant composed of $33 \% \mathrm{CH}_{3} \mathrm{COOH}+33 \% \mathrm{HNO}_{3}+33 \% \mathrm{H}_{2} \mathrm{O}+$ $1 \% \mathrm{HF}$ by volume. A scanning electron microscope (FEI Qunta 200 F) equipped with energy dispersion spectroscopy (EDS) was used to study the polished samples. The volume fractions of different phases were measured using Dwinter material plus software. The phases present in different specimen were identified using EDS and XRD. For XRD studies on polished samples, an X-ray diffractometer (D8-Advance Bruker-axe) was used with $\mathrm{Cu} \mathrm{K}_{\alpha}$ radiation $(\lambda=1.5405)$. The bulk hardness of the alloys was measured using a FIEVM50 PC Vickers hardness tester at a load of $10 \mathrm{~kg}$. The microhardness of different phases was measured using a load of $25 \mathrm{~g}$ in a VHM-002 Walter UHL hardness tester. The compressive test specimens of 6-mm diameter and 9-mm length 
Table 1. Nominal composition and volume fraction of different phases of alloys.

\begin{tabular}{|c|c|c|c|c|c|c|c|c|c|}
\hline \multicolumn{5}{|c|}{ Compositions (wt\%) } & \multicolumn{5}{|c|}{ Volume fraction of various phases (\%) } \\
\hline Alloys & $\mathrm{Al}$ & $\mathrm{C}$ & $\mathrm{Ti}$ or $\mathrm{Zr}$ & $\mathrm{Fe}$ & Graphite & $\mathrm{Fe}_{3} \mathrm{AlC}_{0.5}$ & $\mathrm{TiC}$ & $\mathrm{ZrC}$ & $\mathrm{Zr}(\mathrm{Fe}, \mathrm{Al})_{2}$ \\
\hline Alloy-1 & 22.0 & 1.0 & - & Balance & $<3.0$ & $12-14$ & - & - & - \\
\hline Alloy-2 & 22.0 & 1.0 & $5.0(\mathrm{Zr})$ & Balance & - & - & - & $11-13$ & $6-8$ \\
\hline Alloy-3 & 22.0 & 1.0 & $5.0(\mathrm{Ti})$ & Balance & - & - & $14-17$ & - & - \\
\hline Alloy-4 & 22.0 & 1.5 & $5.0(\mathrm{Ti})$ & Balance & - & - & $20-23$ & - & - \\
\hline
\end{tabular}

were cut from the ingots by electro-discharge machining. The tests were performed using an S-series H75K-S tensile testing machine at a constant strain rate of $10^{-4} \mathrm{~s}^{-1}$ at room temperature.

The dry sliding wear tests were carried out using a ballon-disc apparatus. Specimens with size of $12 \times 12 \times 5 \mathrm{~mm}^{3}$ were used. The specimen was polished with different grades of emery papers and then finally cloth polished using $0.5-\mu \mathrm{m}$ grade alumina powder finish. The surface roughness of polished and wear surfaces was measured using a surface profiler (Mytutoyo SJ-400, Japan). SiC balls (6-mm diameter and hardness $25-28 \mathrm{GPa}$ ) were used as the counter-material. The wear tests were conducted at different sliding speeds of $0.1,0.21$ and $0.31 \mathrm{~m} \mathrm{~s}^{-1}$ to the total distance of 124,252 and $377 \mathrm{~m}$. The applied loads were 5, 10 and $20 \mathrm{~N}$ with testing time of $20 \mathrm{~min}$. Three different wear tracks with diameters 4, 8 and $12 \mathrm{~mm}$ were used for each specimen. The wear rate was evaluated by dividing the volume of the wear scar by the load and the sliding distance. The depth of wear track of various specimens was also measured with the profiler. Averages of three different readings were taken. The friction force and coefficient of friction were obtained automatically. The morphologies of worn surfaces of all the samples were studied using scanning electron microscopy (SEM) to understand the wear mechanism.

\section{Results and discussion}

\subsection{Microstructural characterization}

Microstructure of Alloy-1 exhibits three phases. These phases are identified in figure 1 as $\mathrm{FeAl}$ (matrix), graphite with dark star shape (region $\mathrm{A}$ ) and $\mathrm{Fe}_{3} \mathrm{AlC}_{0.5}$ phase (region $\mathrm{B})$, which forms a continuous network at the FeAl grain boundaries. $\mathrm{Fe}_{3} \mathrm{AlC}_{0.5}$ precipitate is observed to have an average width of $5 \mu \mathrm{m}$. The average width and length of the graphite flake is found to be $\sim 3$ and $55 \mu \mathrm{m}$, respectively. EDS results show that the region $\mathrm{B}$ comprises $\mathrm{Fe}, \mathrm{Al}$ and $\mathrm{C}$. Alloy-2 (figure 2) consists of cuboid-shaped $\mathrm{ZrC}$ (region $\mathrm{C}$ ), an $\mathrm{FeAl}$ matrix and fine precipitates (region D) at the grain boundaries. The average edge size of $\mathrm{ZrC}$ carbides is found to be $\sim 10 \mu \mathrm{m}$. The results of EDS analysis reveal that cubiodshaped particle (region $\mathrm{C}$ ) is comprised of $\mathrm{Zr}$ and $\mathrm{C}$, whereas particles along the grain boundaries show the presence of $\mathrm{Zr}, \mathrm{Al}$ and $\mathrm{Fe}$ and may be the Laves phase $\mathrm{Zr}(\mathrm{FeAl})_{2}$.
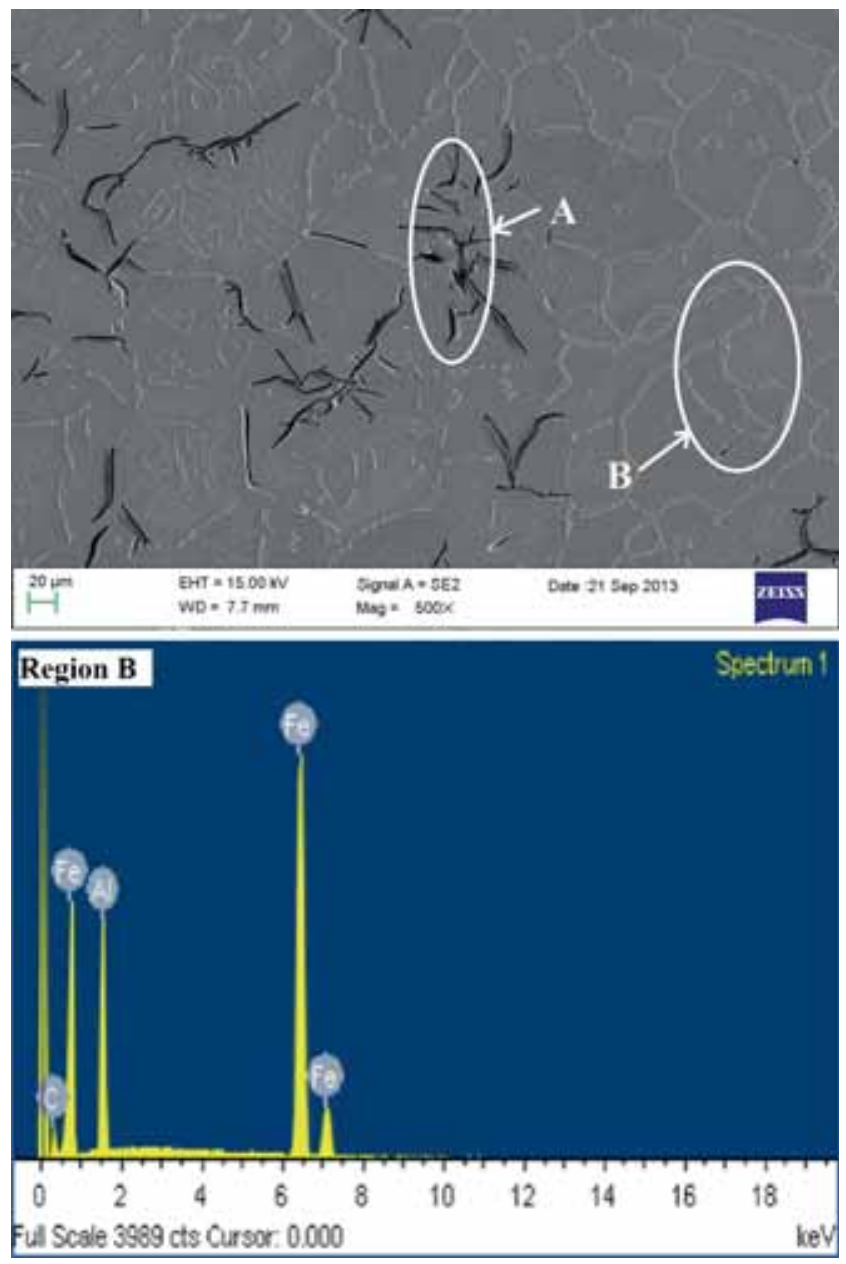

Figure 1. SEM micrographs and EDS analysis of carbides of Alloy-1 with network structure of graphite flakes (region A) and $\mathrm{Fe}_{3} \mathrm{AlC}_{0.5}$ carbides (region $\mathrm{B}$ ).

Alloy-3 (figure 3a) exhibits three phases with cuboidshaped $\mathrm{TiC}$ (region $\mathrm{E}$ ) and elongated $\mathrm{Fe}_{3} \mathrm{AlC}_{0.5}$ (region $\mathrm{F}$ ) in FeAl matrix. The average edge size of $\mathrm{TiC}$ is $\sim 15 \mu \mathrm{m}$, while the average width and length of $\mathrm{Fe}_{3} \mathrm{AlC}_{0.5}$ carbide is found to be $\sim 2$ and $\sim 20 \mu \mathrm{m}$, respectively. A similar microstructure is obtained for Alloy-4 (figure 3b) where only the carbon content is increased from 1.0 to 1.5 and hence the volume fraction and size of carbides are found to increase. The average edge size of $\mathrm{TiC}$ is $\sim 25 \mu \mathrm{m}$, whereas the average width and length of $\mathrm{Fe}_{3} \mathrm{AlC}_{0.5}$ carbide are found to be $\sim 2$ and $\sim 30 \mu \mathrm{m}$, 

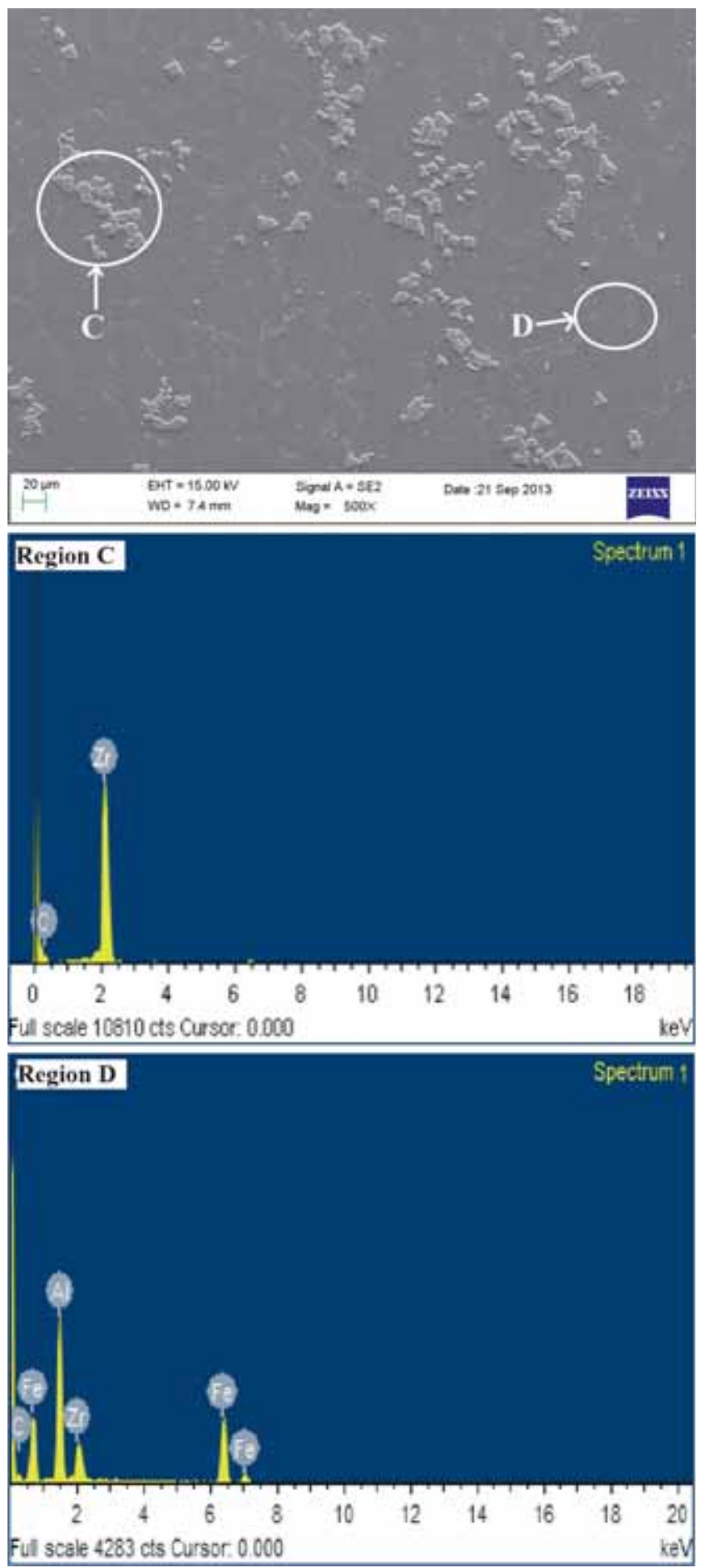

Figure 2. SEM micrographs and EDS analysis of carbides of Alloy-2 with cuboid $\mathrm{ZrC}$ (region $\mathrm{C}$ ) and Laves phase $\mathrm{Zr}(\mathrm{FeAl})_{2}$ (region D).

respectively. EDS results reveal that the cuboid-shaped particle (region $\mathrm{E}$ ) is composed of $\mathrm{Ti}$ and $\mathrm{C}$ and elongated one (region F) comprises of $\mathrm{Fe}, \mathrm{Al}$ and $\mathrm{C}$. The volume fraction of different carbides increased with increase in the carbon content as given in table 2.

The XRD patterns of alloys are shown in figure 4. XRD pattern of Alloy-1 confirms the presence of $\mathrm{Fe}_{3} \mathrm{AlC}_{0.5}$ with (a)

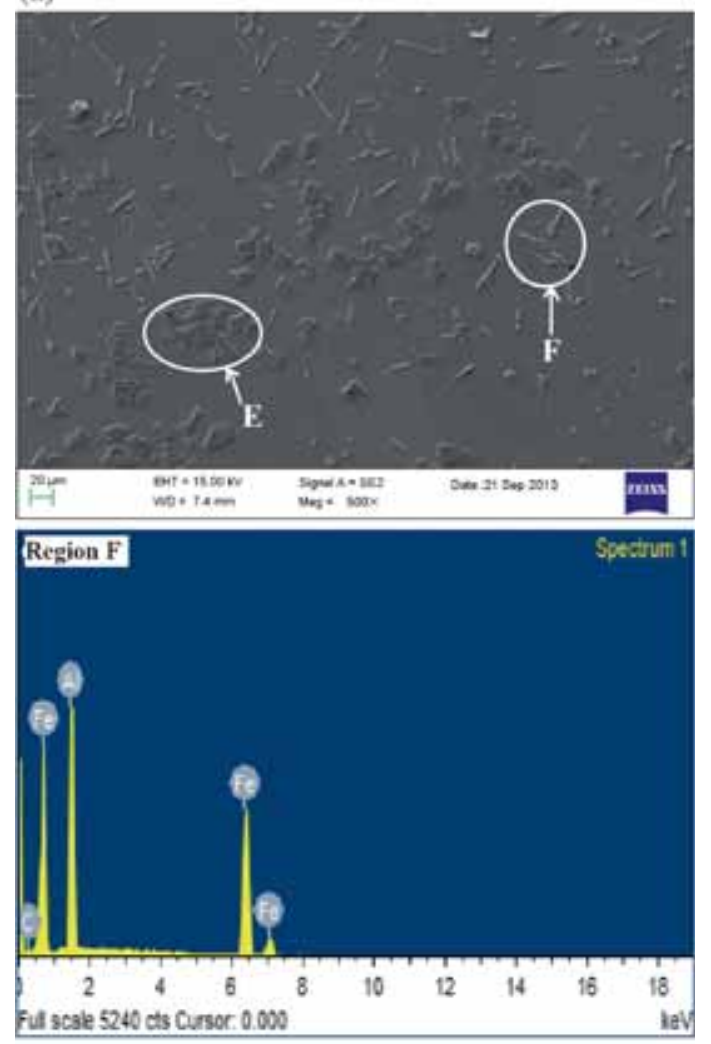

(b)
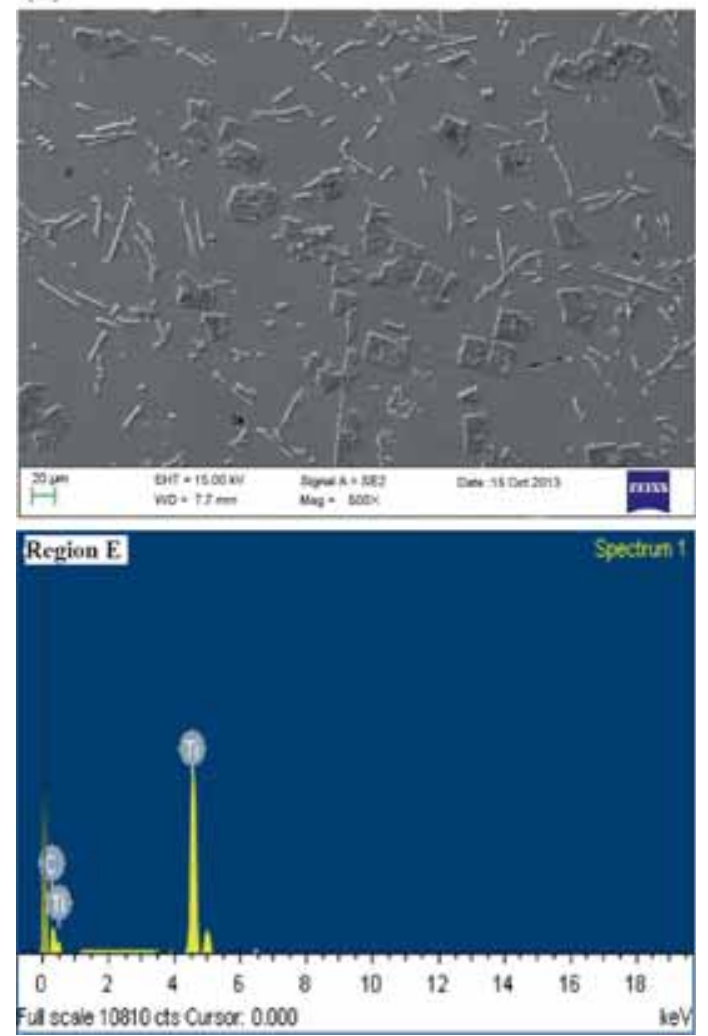

Figure 3. SEM micrographs and EDS analysis of carbides of (a) Alloy-3 with cuboid $\mathrm{TiC}$ (region $\mathrm{E}$ ) and elongated $\mathrm{Fe}_{3} \mathrm{AlC}_{0.5}$ carbide particles (region F) and (b) Alloy-4 with similar carbide particles. 
Table 2. Bulk hardness, microhardness and compressive strength of various alloys listed below.

\begin{tabular}{lccccc}
\hline & & \multicolumn{3}{c}{ Microhardness values (Hv) } & \\
\cline { 3 - 5 } Alloys & Bulk hardness (Hv) & Matrix & $\mathrm{Fe}_{3} \mathrm{AlC}_{0.5}$ & $\mathrm{TiC}$ or ZrC & Compressive yield strength (MPa) \\
\hline Alloy-1 & 385 & 350 & 600 & - & 900 \\
Alloy-2 & 400 & 380 & - & 2650 & 1000 \\
Alloy-3 & 425 & 410 & 610 & 3000 & 1050 \\
Alloy-4 & 470 & 410 & 610 & 3000 & 1200 \\
\hline
\end{tabular}

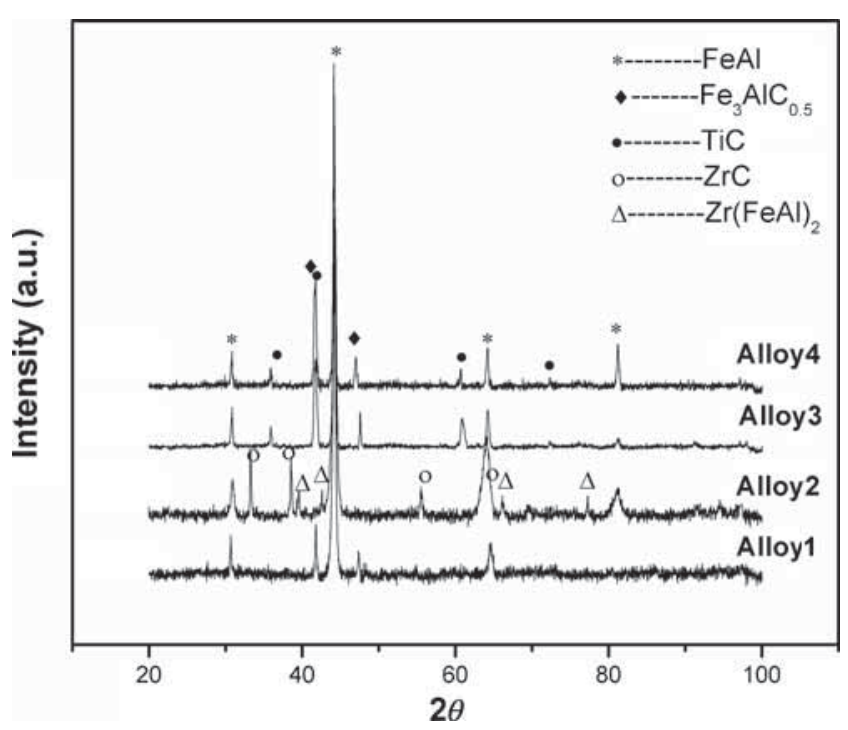

Figure 4. XRD patterns obtained from all FeAl-based alloys.

ordered $\mathrm{B} 2 \mathrm{FeAl}$ matrix. The peaks of graphite in Alloy-1 are not observed in the XRD pattern (figure 4), indicating that the volume fraction of graphite is low $(<3 \%)$. In Alloy2, XRD indicates the presence of $\mathrm{ZrC}$ carbides, a few peaks of Laves phase $\mathrm{Zr}(\mathrm{Fe}, \mathrm{Al})_{2}$ and ordered $\mathrm{B} 2 \mathrm{FeAl}$ matrix. The presence of $\mathrm{TiC}$ and $\mathrm{Fe}_{3} \mathrm{AlC}_{0.5}$ with ordered $\mathrm{B} 2 \mathrm{FeAl}$ matrix in Alloy-3 and Alloy-4 is also confirmed by XRD analysis as shown in figure 4.

All alloys exhibit FeAl-based matrix with B2 ordered structure. Both $\mathrm{Zr}$ and $\mathrm{Ti}$ have affinity to $\mathrm{C}$ and from $\mathrm{ZrC} / \mathrm{TiC}$, thus preventing the formation of graphite. No $\mathrm{Fe}_{3} \mathrm{AlC}_{0.5}$ carbides were observed in Alloy-2. SEM images of these alloys were used to calculate the volume fraction of various phases observed (table 1). The software was unable to distinguish $\mathrm{Fe}_{3} \mathrm{AlC}_{0.5}$ and $\mathrm{TiC}$ carbides in Alloy-3 and Alloy- 4 and therefore a combined carbide volume fraction is reported.

\subsection{Mechanical properties}

3.2a Hardness and compression: The mechanical properties of alloys are given in table 2. An average of three tests was taken to determine these values. Alloy-1 exhibits low strength and hardness because of the graphite present in the alloy. Alloy-2 and Alloy-3 exhibit comparable values of strength and hardness but higher than those of Alloy-1 due to the presence of hard $\mathrm{ZrC}$ and $\mathrm{TiC}$ carbides, respectively.
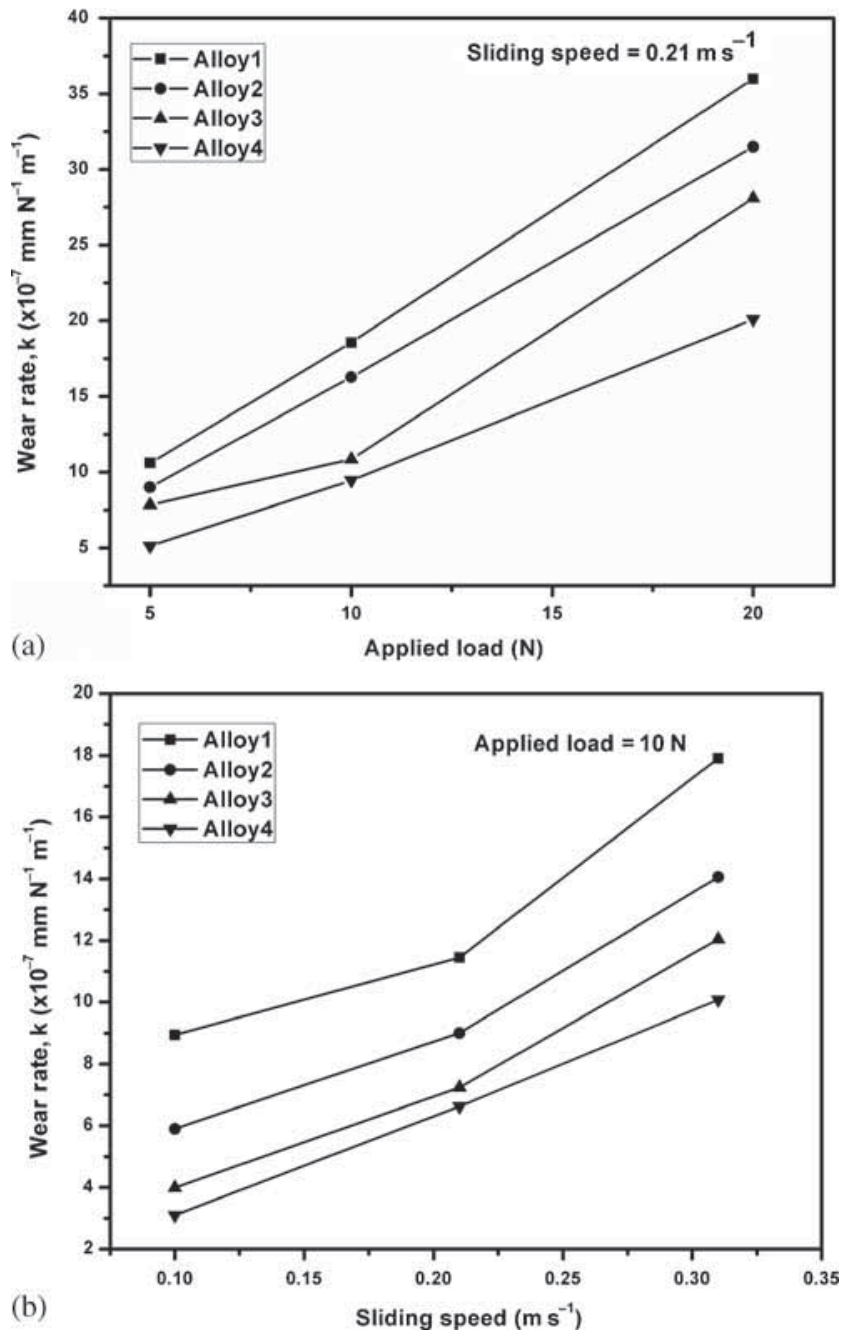

Figure 5. The variation of wear rate of FeAl-based alloy: (a) applied loads and (b) sliding speeds.

In Alloy-2 and Alloy-3, the matrix hardness also shows some improvement due to limited solubility of $\mathrm{Zr} / \mathrm{Ti}$ in $\mathrm{FeAl}$ $[10,23]$. There is no change in matrix hardness on increasing the carbon content from 1\% (Alloy-3) to 1.5\% (Alloy-4), indicating that no further carbon has gone into the matrix. $\mathrm{ZrC}$ and $\mathrm{TiC}$ precipitates have higher values of hardness than that of $\mathrm{Fe}_{3} \mathrm{AlC}_{0.5}$. Lower volume fraction of carbides results in lower strength and hardness in Alloy-2 compared with Alloy-3. Alloy-4, which has the highest carbon (and carbide) content, exhibited the highest values of hardness and strength. Thus strength of these alloys is determined by the volume fraction and hardness of carbides present. 


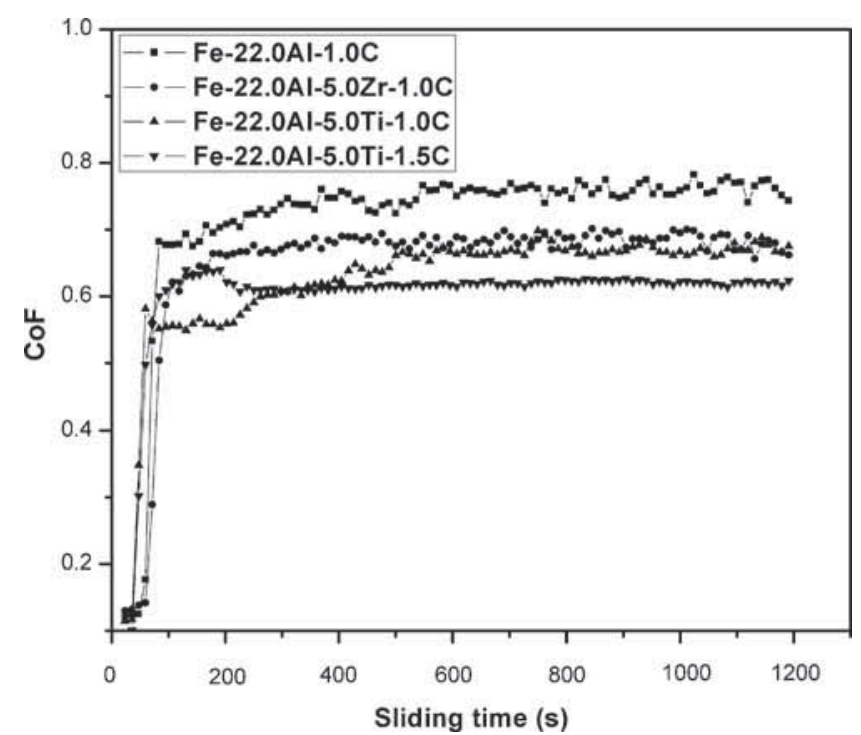

Figure 6. The variation of coefficient of friction $(\mathrm{CoF})$ with time for FeAl-based alloys at applied load $10 \mathrm{~N}$ with sliding speed $0.21 \mathrm{~m} \mathrm{~s}^{-1}$.

3.2b Wear: Wear rate from wear test of FeAl-based alloys is plotted $v s$. applied load at different sliding speeds. The wear rate $k\left(\mathrm{~mm}^{3}(\mathrm{Nm})^{-1}\right)$ is given by

$$
k=\Delta V / F S,
$$

where $\Delta V$ is the volume loss $\left(\mathrm{mm}^{3}\right), F$ the applied load $(\mathrm{N})$ and $S$ the sliding distance $(\mathrm{m})$.

The wear rate increases as applied load increases (figure 5a). Alloy-1 shows the highest wear rate among the alloys. Alloy-2 has a moderate wear rate. Alloy-3 and Alloy4 with the same Ti content show significant wear rate difference under the given test conditions. Among all the alloys, Alloy-4 shows the lowest wear rate. During sliding wear, the surface of the material is removed initially and load is mainly transferred to the carbide particles. Thus, the hardness of the carbide particles plays an important role under the applied load. Carbides with high hardness (here TiC) lead to lower wear rate.

The wear rate of $\mathrm{FeAl}$-based alloys is plotted as a function of the sliding speed in figure $5 \mathrm{~b}$. The wear rate increases with higher speed. Alloy-1 shows the highest wear rate. Alloy3 and Alloy-4 show less wear rate difference at slow speed but the difference becomes significant at higher speed with Alloy-3 exhibiting higher wear rate than that of Alloy- 4 . Alloy-4 exhibits the lowest wear rate among the alloys. This is because the higher sliding speed increases frequency of cyclic stress. This may encourage breakage of the particulates by dislocation shearing under plastic deformation. At the same time, matrix oxidation, removal of the rapidly grown oxide film and subsurface matrix softening due to high frictional temperature conditions may also be effective. The increase of frictional energy consumed in the form of heat energy at higher sliding speeds softens the matrix. This may allow easier pull-out of carbide particles

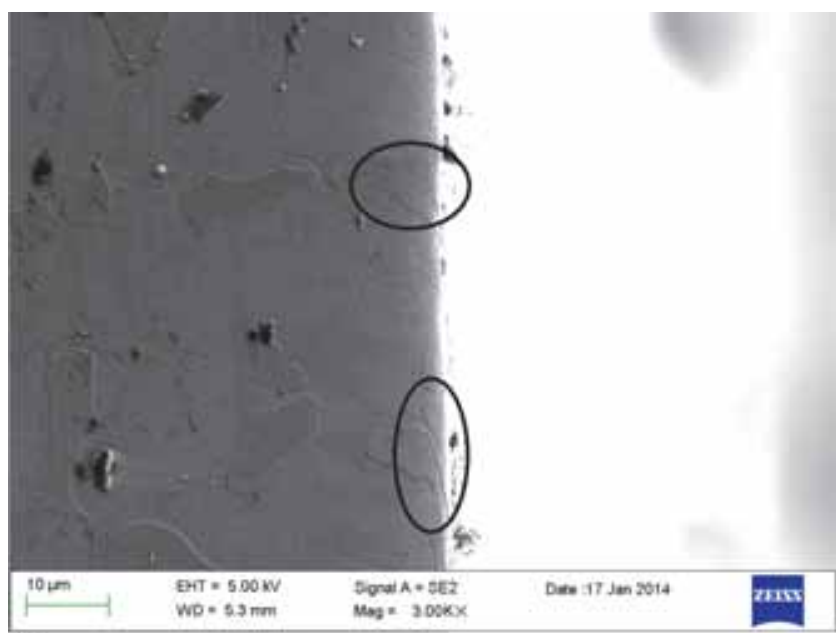

(a)

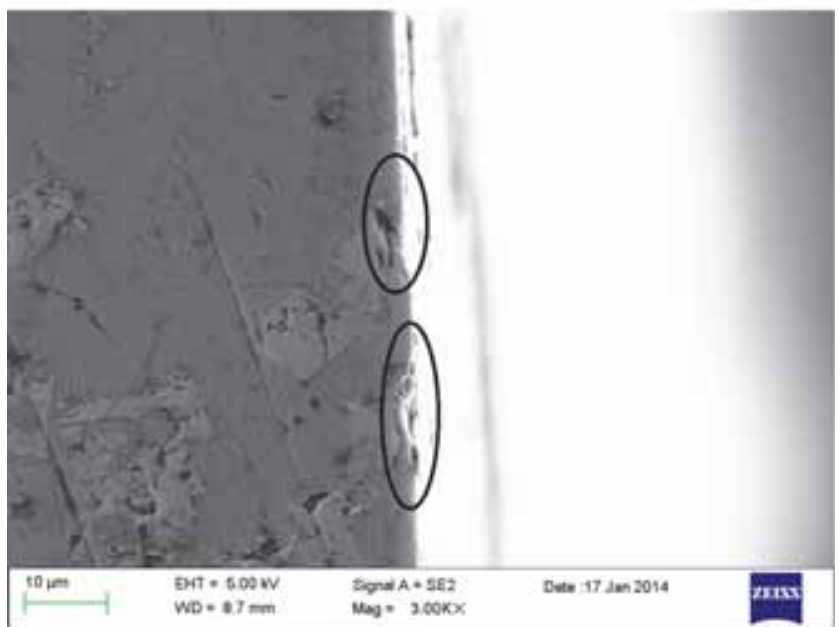

(b)

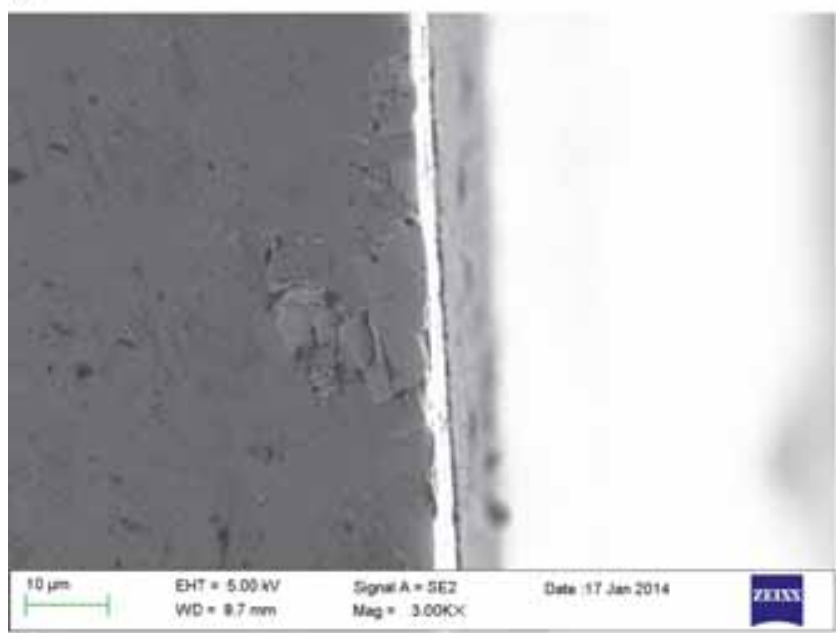

(c)

Figure 7. Cross-section of wear tracks of (a) Alloy-1, (b) Alloy-2 and (c) Alloy-3 showing different carbides embedded in matrix after sliding wear.

due to weakened interface. Thus, the wear rate of alloys increases with the sliding speed.

Figure 6 shows the coefficients of friction for all alloys tested at applied load of $10 \mathrm{~N}$ with sliding velocity 


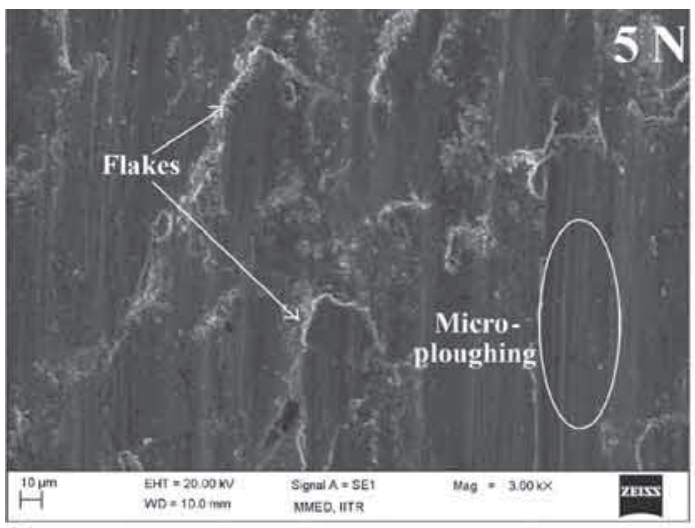

(a)

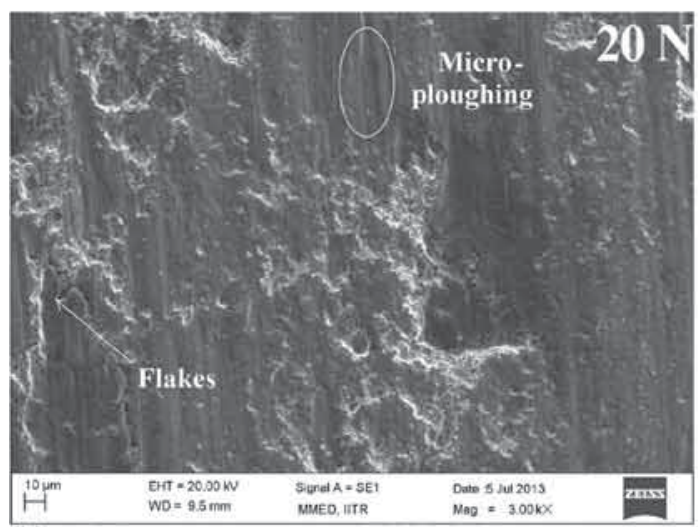

(b)

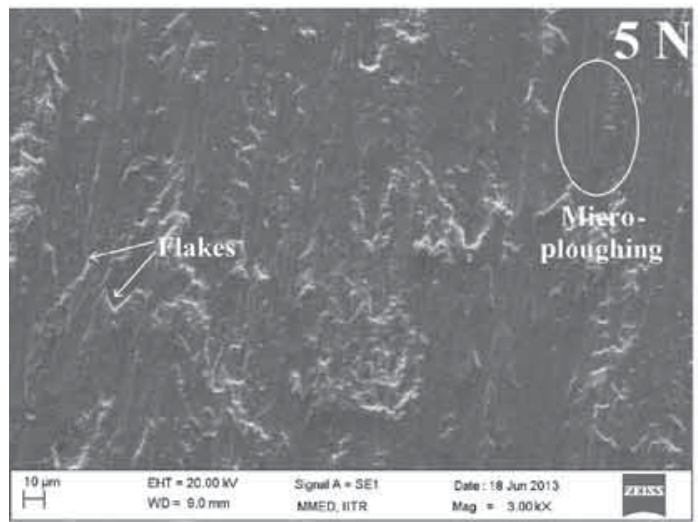

(c)

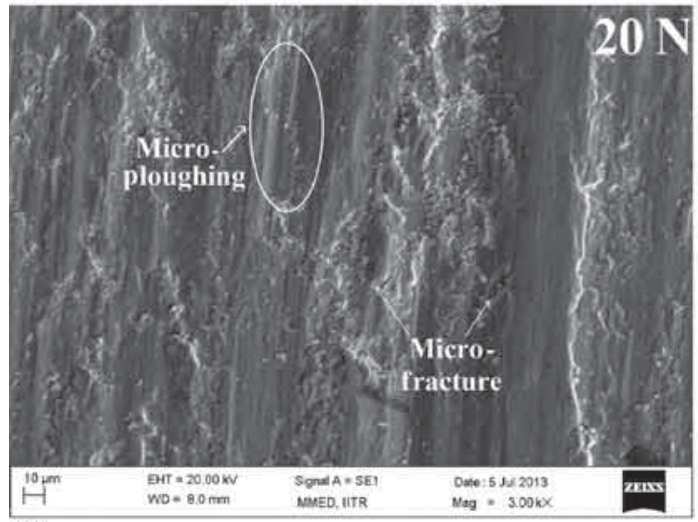

(d)

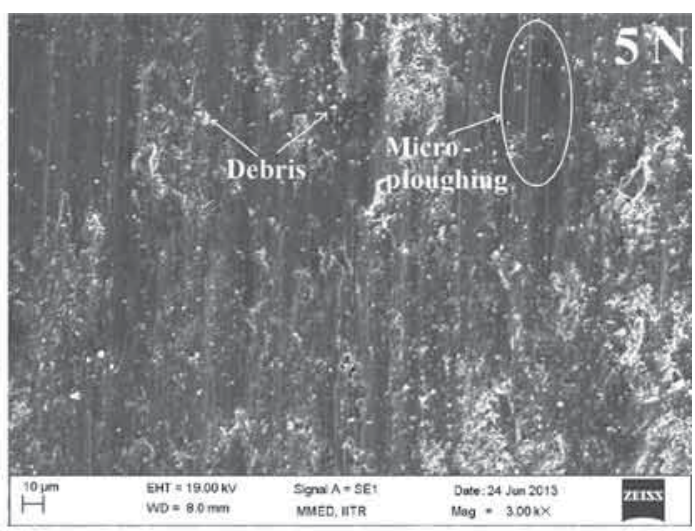

(e)

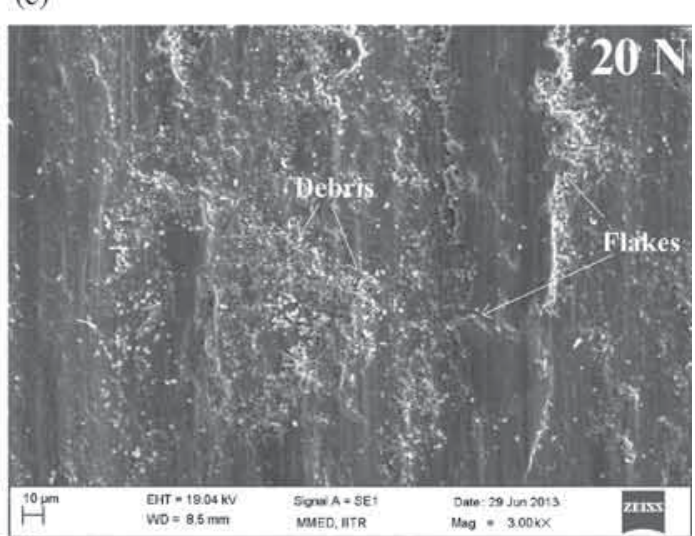

(f)

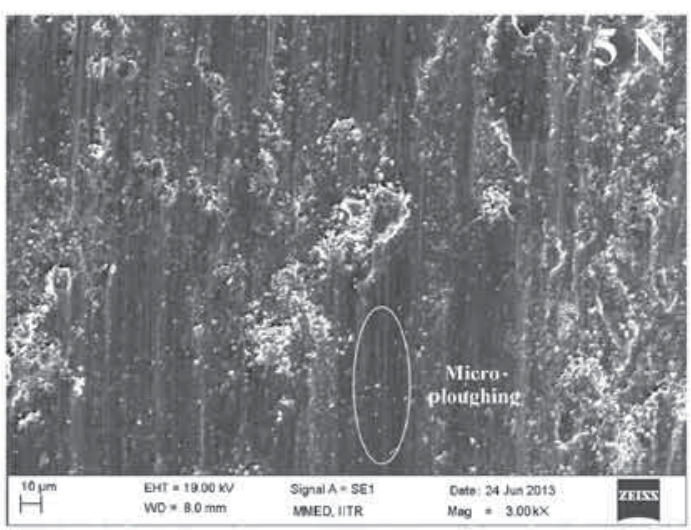

(g)

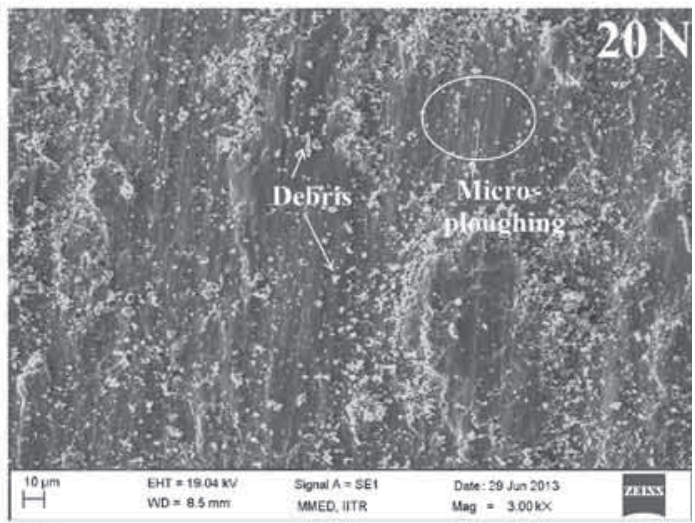

(h)

Figure 8. SEM micrographs showing morphologies of wear tracks for (a, b) Alloy-1, (c, d) Alloy-2, (e, f) Alloy-3 and $(\mathbf{g}, \mathbf{h})$ Alloy-4 at applied load 5 and $20 \mathrm{~N}$ with sliding speed $0.21 \mathrm{~m} \mathrm{~s}^{-1}$. 
$0.21 \mathrm{~m} \mathrm{~s}^{-1}$. The coefficient of friction increases sharply after initial fluctuations and acquires a relatively steady state, which prevails (figure 6 ). This indicates that hard carbide particles ( $\mathrm{ZrC}$ in Alloy-2, TiC in Alloy-3 and Alloy-4) in matrix lower the shear and therefore contact area is much smaller. This leads to decrease in the coefficient of friction. Thus the coefficient of friction is strongly affected by the presence of hard $\mathrm{ZrC}$ and $\mathrm{TiC}$ carbides in FeAl-based alloys. It is well known that high friction coefficient results in higher wear rate [24].

Figure 7a shows the deformation of $\mathrm{Fe}_{3} \mathrm{AlC}_{0.5}$ carbide in sliding wear direction. Thus, deformation of $\mathrm{Fe}_{3} \mathrm{AlC}_{0.5}$ carbide would result in a higher friction coefficient of Alloy-1 than others. It may also be observed that the graphite flakes in Alloy-1 has lower load-bearing capacity. Thus, the deformation of $\mathrm{Fe}_{3} \mathrm{AlC}_{0.5}$ carbides in the sliding direction with a few graphite flakes enhanced the wear rate. On the other hand, the carbides such as $\mathrm{ZrC}$ and $\mathrm{TiC}$ in Alloy-2, Alloy3 and Alloy- 4 are embedded in the matrix even after sliding wear without any deformation. Figure $7 \mathrm{~b}$ and $\mathrm{c}$ shows the cross-sectional area of the wear tracks of the alloys. It reveals that the carbides, mainly $\mathrm{ZrC}$ and $\mathrm{TiC}$ in Alloy-2 and Alloy-3, respectively, have very little effect of applied load. This strongly indicates that these carbides affect the wear rate of $\mathrm{FeAl}$ alloys without delamination or destruction while $\mathrm{Fe}_{3} \mathrm{AlC}_{0.5}$ carbide starts to deform in sliding direction under the applied load. This deformation of $\mathrm{Fe}_{3} \mathrm{AlC}_{0.5}$ carbides results in higher wear rate of Alloy-1.

Thus, the dispersion of carbides improves the wear resistance and friction coefficient of FeAl-based alloys. The hardness values of $\mathrm{TiC}$ or $\mathrm{ZrC}$ are significantly higher than that of $\mathrm{Fe}_{3} \mathrm{AlC}_{0.5}$ carbide. Also, no graphite precipitates are observed in these alloys (Alloy-2, Alloy-3 and Alloy-4). Therefore, the results demonstrate that uniform distribution of fine carbides in FeAl-based alloys works more effectively for wear resistance. These results also reflect that the wear rate of FeAl-based alloys decreased because different carbide particles play supporting role during the sliding wear. The microhardness difference between $\mathrm{TiC}$ and $\mathrm{ZrC}$ is not very large; thus wear rate should be similar. The compatibility issue among the matrix and the reinforcement plays an important role. $\mathrm{TiC}$ is found to be more compatible with $\mathrm{FeAl}$ matrix in comparison with $\mathrm{ZrC}$ [25]. This is due to the low CTE (coefficient of thermal expansion) mismatch between $\mathrm{TiC}$ and $\mathrm{FeAl}$ in comparison with $\mathrm{ZrC}$ and $\mathrm{FeAl}$ [25]. The observations clearly indicate that $\mathrm{TiC}$ is more compatible with $\mathrm{FeAl}$ matrix than $\mathrm{ZrC}$. Also, most of the literature is on composites fabricated through PM route where bonding between matrix and ceramic particles is a major issue and leads to poor properties [26].

SEM micrographs of the wear tracks for different alloys are shown in figure 8. In general, the shear stress among the contact surfaces increased with increase in the applied load. A few lines in the friction surface with very small flakes would be initiated at lower applied load (figure 8a, c, e and g), while much more flakes would be produced and are more responsible for propagation at higher applied load (figure $8 \mathrm{~b}, \mathrm{~d}, \mathrm{f}$ and $\mathrm{h}$ ). Thus, the wear rate in general of all alloys enhanced with increase in the applied load. The micrographs were taken after the sliding wear test conducted at different applied loads. In the mild testing conditions, i.e., low normal load and sliding speed, the surfaces show small flakes with fine debris and traces of microploughing were observed as shown in figure 8. However, in the severe conditions, i.e., at high normal load, the surface appearance was quite different. The wear surfaces were covered with deep grooves and flaking pits. The wear scars were heavily damaged, and the platelets and a trace of their detachment from the surface were observed together with the micro-ploughing.

During the sliding wear, the strains accumulate at the contacting points between the asperities, which subsequently form the surface deformation layers with increased dislocation density. The delamination is mainly due to cracking along the region of high dislocation density [27]. This effect is more pronounced in Alloy-2, Alloy-3 and Alloy-4 due to hard $\mathrm{ZrC}$ and $\mathrm{TiC}$ precipitates, respectively. Compared with $\mathrm{Fe}_{3} \mathrm{AlC}_{0.5}$, the higher hardness of both $\mathrm{ZrC}$ and $\mathrm{TiC}$ seems to play a positive role in resisting the wear damage from the counter-face and thus makes the process of delamination more difficult.

\section{Conclusions}

(1) The addition of transition alloying elements such as $\mathrm{Zr}$ and $\mathrm{Ti}$ to FeAl-based alloys containing carbon resulted in increase in the strength and hardness. This increase is mainly attributed to the precipitation of hard carbides ( $\mathrm{ZrC} / \mathrm{TiC}) . \mathrm{Zr}$ addition results in precipitation of hard $\mathrm{ZrC}$ and Laves phase $\mathrm{Zr}(\mathrm{FeAl})_{2}$. Ti addition causes precipitation of hard TiC. No graphite precipitation was observed in FeAl-based alloys on $\mathrm{Zr}$ and Ti addition.

(2) With addition of $\mathrm{Ti}$ and $\mathrm{Zr}$, the coefficient of friction and wear rate of FeAl-based alloys decreased due to higher hardness of $\mathrm{TiC}$ and $\mathrm{ZrC}$, respectively.

(3) Wear mechanism of FeAl-based alloys was transferred from the micro-ploughing to micro-fracture and their detachment from the surface with applied load and sliding speed.

(4) The hardness, strength and wear rate of these alloys are determined by the volume fraction and hardness of carbides present.

(5) The in-situ production of carbides provides good bonding between the carbides and matrix and hence improves the wear resistance of FeAl alloys as compared with composites of iron aluminides mostly prepared using the powder metallurgy route.

\section{Acknowledgement}

This research has been supported by the Department of Science and Technology, New Delhi, and we are thankful for the financial support. 


\section{References}

[1] Deevi S C and Sikka V K 1996 Intermetallics 4357

[2] Mckamey C G and Stoloff N S 1996 in: Physical metallurgy and processing of intermetallic compounds (eds) N S Stoloff and V K Sikka p 351

[3] Prakash U 2008 Trans. Indian Inst. Met. 61193

[4] Prakash U and Sauthoff G 2001 Scr. Mater. 4473

[5] Sundar R S and Deevi S C 2003 Metall. Mater. Trans. A 34 2233

[6] Alman D E, Hawk J A, Tylczak J H, Dogan C P and Wilson R D 2001 Wear 251875

[7] Radhakrishna A, Baligidad R G and Sarma D S 2001 Scr. Mater. 451077

[8] Kopecek J, Hausild P, Jurek K, Jarosova M, Drahokoupil J, Novak P and Sima V 2010 Intermetallics 181327

[9] Kuzucu V, Aksoy M and Korkut M H 1998 J. Process. Technol. 82165

[10] Kant R, Prakash U, Agarwala V and Satyaprasad V V 2015 Trans. Indian Inst. Met. doi: 10.1007/s12666-015-0567-z

[11] Guan X, Iwasaki K, Kishi K, Yamamoto M and Tanaka R 2004 Mater. Sci. Eng. A 366127
[12] Kant R, Prakash U, Agarwala V and Satyaprasad V V 2015 Intermetallics 6121

[13] Zhang X, Ma J, Yang J, Bi Q and Liu W 2011 Wear 271881

[14] Palm M and Sauthoff G 2004 Intermetallics 121345

[15] Stein F, Sauthoff G and Palm M 2004 Z. Metallkd. 95469

[16] Kratochvila P, Dobes F, Pesicka J, Malek P, Bursik J, Vodickova V and Hanus P 2012 Mater. Sci. Eng. A 548175

[17] Hawk J A and Alman D E 1993 Wear 225-229 544

[18] Mosbah A Y, Wexler D and Calka A 2005 Wear 2581337

[19] Subramanian R and Schneibel J H 1998 Mater. Sci. Eng. A 244103

[20] Aikin R M 1997 J. Min. Met. Mater. Soc. 4935

[21] Raghunath C, Bhat M S and Rohatgi P K 1995 Scr. Metall. 32 577

[22] Terry B S and Chinyamakobvu O S 1991 J. Mater. Sci. Lett. 10628

[23] Palm M 2005 Intermetallics 131286

[24] Qiu J, Baker I, Kennedy F E, Liu Y and Munroe P R 2013 Intermetallics $\mathbf{4 0} 19$

[25] Houska C R 1964 J. Phys. Chem. Solids 25359

[26] Subramanian R and Schniebel J H 1997 J. Min. Met. Mater. Soc. 4950

[27] Kim Y S and Kim Y H 1998 Mater. Sci. Eng. A 258319 